OPEN ACCESS

Edited by:

Marcos Fabio DosSantos,

Federal University of Rio de

Janeiro, Brazil

Reviewed by:

Diana Spicarova,

Academy of Sciences of the Czech

Republic (ASCR), Czechia

Antti Pertovaara

University of Helsinki, Finland

${ }^{*}$ Correspondence.

Cyril Schneider

Cyril.schneider@rea.ulaval.ca

†These authors share first authorship

Specialty section:

This article was submitted to

Pain Mechanisms,

a section of the journal

Frontiers in Pain Research

Received: 28 June 2021

Accepted: 23 August 2021

Published: 21 September 2021

Citation:

Zangrandi A, Allen Demers F and

Schneider C (2021) Complex Regional

Pain Syndrome. A Comprehensive

Review on Neuroplastic Changes

Supporting the Use of Non-invasive

Neurostimulation in Clinical Settings.

Front. Pain Res. 2:732343.

doi: 10.3389/fpain.2021.732343

\section{Complex Regional Pain Syndrome. A Comprehensive Review on Neuroplastic Changes Supporting the Use of Non-invasive Neurostimulation in Clinical Settings}

\author{
Andrea Zangrandi ${ }^{1,2,3+}$, Fannie Allen Demers ${ }^{1,2,3+}$ and Cyril Schneider ${ }^{1,2,3,4 *}$ \\ ${ }^{1}$ Noninvasive Neurostimulation Laboratory (NovaStim), Quebec City, QC, Canada, ${ }^{2}$ Neuroscience Division of Centre de \\ Recherche du CHU of Québec, Université Laval, Quebec City, QC, Canada, ${ }^{3}$ Faculty of Medicine, Université Laval, Quebec \\ City, QC, Canada, ${ }^{4}$ Department Rehabilitation, Université Laval, Quebec City, QC, Canada
}

Background: Complex regional pain syndrome (CRPS) is a rare debilitating disorder characterized by severe pain affecting one or more limbs. CRPS presents a complex multifactorial physiopathology. The peripheral and sensorimotor abnormalities reflect maladaptive changes of the central nervous system. These changes of volume, connectivity, activation, metabolism, etc., could be the keys to understand chronicization, refractoriness to conventional treatment, and developing more efficient treatments.

Objective: This review discusses the use of non-pharmacological, non-invasive neurostimulation techniques in CRPS, with regard to the CRPS physiopathology, brain changes underlying chronicization, conventional approaches to treat CRPS, current evidence, and mechanisms of action of peripheral and brain stimulation.

Conclusion: Future work is warranted to foster the evidence of the efficacy of non-invasive neurostimulation in CRPS. It seems that the approach has to be individualized owing to the integrity of the brain and corticospinal function. Non-invasive neurostimulation of the brain or of nerve/muscles/spinal roots, alone or in combination with conventional therapy, represents a fertile ground to develop more efficient approaches for pain management in CRPS.

Keywords: complex regional pain syndrome (CRPS), non-invasive neurostimulation techniques, rTMS, rPMS, tDCS, TENS, maladaptive plasticity, chronic pain

\section{INTRODUCTION}

Complex regional pain syndrome (CRPS) is a rare debilitating disorder characterized by severe and persisting pain affecting one or more limbs. Signs and symptoms are disproportionate owing to the inciting event and include spontaneous and/or movement-induced pain, sensory impairment (allodynia, hyperesthesia), autonomic dysregulation (changes in skin temperature and/or color, abnormal sweating), and motor abnormalities (joint stiffness, tremor, dystonia, and muscle weakness). The inciting event is usually traumatic, such as fracture, surgery outcome, sprain, 
or contusion, but in $\sim 10 \%$ of cases, the precipitating cause remains unknown. CRPS is divided into two main categories based on the absence (type I, 90\% of cases) or presence (type II) of nerve lesion at the periphery (1). A third type ("Not Otherwise Specified, or "NOS") includes patients who do not fulfill the diagnosis criteria, but whose signs and symptoms cannot be better explained by another diagnosis (2). Also, people who were diagnosed only at a later stage when some of the symptoms were resolved can enter the NOS category (although retrospective inspection of medical history shows that they would have fulfilled all criteria for CRPS diagnosis if only they had been assessed at an earlier stage). Due to the variety and complexity of its symptoms and the initial lack of recognition as a disease, CRPS was historically referred to different names [e.g., reflex sympathetic dystrophy, RSD; algodystrophy; causalgia; shoulder-hand syndrome; etc., refer to Merskey (3)]. The 1994 International Association for the Study of Pain (IASP) adopted the appellation of CRPS and affined the diagnosis by establishing specific descriptive criteria. The latter was then improved by the "Budapest Criteria" (refer to Table 1) (2), which are in use even today to diagnose CRPS $(4,5)$.

Complex regional pain syndrome mostly occurs in the age range of 40-70 years (median of 46 years), three to four times more frequently in women (6) and rarely in children $(<10 \%$ of cases, usually in early adolescence) (7). CRPS worldwide prevalence varies from 5.5 to 26.2 per 100,000 persons per year $(8,9)$. The upper limb is more often affected (almost $60 \%$ of cases) than the lower limb and most cases resolve within the first year (10). But CRPS evolves into a chronic condition in $15-20 \%$ of cases, hindering daily life activities and overall quality of life and

TABLE 1 | The "Budapest Criteria" for complex regional pain syndrome (CRPS) diagnosis*.

1. Continuing pain, which is disproportionate to any inciting event

2. Must report at least one symptom on three of the four following categories (clinical diagnosis) OR in all four (research purpose):

Sensory hyperesthesia and/or allodynia

Vasomotor: temperature asymmetry and/or skin color changes and/or skin color asymmetry

Sudomotor/edema: edema and/or sweating changes and/or sweating asymmetry

Motor/trophic: decreased range of motion and/or motor dysfunction (weakness, tremor, dystonia) and/or trophic changes (hair, nail, skin)

3. Must display at least one sign at the time of evaluation in two or more of the following categories (clinical criteria and research purpose):

Sensory: evidence of hyperalgesia (to pinpricks) and/or allodynia (to light touch and/or temperature sensation and/or deep somatic pressure and/or joint movement)

Vasomotor: evidence of temperature asymmetry $\left(>1^{\circ} \mathrm{C}\right)$ and/or skin color changes and/or asymmetry

Sudomotor/edema: evidence of edema and/or sweating changes and/or sweating asymmetry

Motor/trophic: evidence of decreased range of motion and/or motor dysfunction (weakness, tremor, dystonia) and/or trophic changes (hair, nail, skin)

4. There is no other diagnosis that better explains the signs and symptoms

Taken from Harden et al. (2). *Diagnosis of CRPS requires to meet all four criteria. preventing $31 \%$ of these cases to be back to work 2 years after the onset of symptoms (11-15).

To date, the pathophysiology of CRPS remains largely discussed as multifactorial (16). Peripheral sensitization, dysregulation of the autonomic nervous system, and immune dysfunction are known to contribute to the occurrence and development of the syndrome. However, the prevalence and intensity of each mechanism involved can vary between patients and over time, thus laying the stress on the difficulty to treat CRPS and the need for individualization of therapeutic approaches $(16,17)$. A growing line of research points out that autonomic and sensorimotor disturbances should be viewed as a manifestation of underlying plastic changes that occur in the central nervous system (CNS) (18-20) and which might be also responsible for the evolution of CRPS into a chronic condition.

The present review discusses the use of non-pharmacological non-invasive neurostimulation techniques in CRPS, with regard to CRPS physiopathology, brain changes underlying chronicization, conventional approaches to treat CRPS, current evidence, and mechanisms of action of peripheral and brain stimulation.

\section{Peripheral Changes and Central Sensitization}

OVERVIEW OF CRPS PHYSIOPATHOLOGY

The inciting trauma of CRPS is usually responsible for the inflammation and the immune cascade that trigger the proliferation of connective tissue cells associated with contracture and of keratinocytes that produce inflammatory cytokines; the inflammatory cytokines activate osteoblasts and osteoclasts responsible for the formation and resorption of the bones. This results in less bone density and sensitization of peripheral nociceptors in CRPS, i.e., a lower pain threshold. Precisely, some C-fibers (nociceptive afferents), which usually only transmit nociceptive information from periphery to spinal cord, begin to produce inflammatory neuropeptides (e.g., Psubstance); these neuropeptides activate mast cells that release in turn chemical mediators associated with the acute phase symptoms, such as the edema, the skin red coloring and warmth, or hair growth $(21,22)$. It follows oxidative stress for the patient in the acute phase, as denoted by a higher number of oxygen free and hydroxyl radicals in the saliva and serum (23). At the chronic stage (symptoms present for 6 months and more), pro-inflammatory factors are still present, but it is reported that the inflammatory profile (presence, among others, of interleukins 1 and 6 in the cerebrospinal fluid and interleukins 1, 2, 4, and 7 in blood samples) is different than during the acute phase (symptoms from $<6$ months; the presence of interleukins 8 and TNF $\alpha$ receptors I and II in the blood) (24). Neurogenic inflammation is also reported in parallel with CNS changes and reciprocal influences are suspected, likely the former influencing the latter in the acute phase and the reverse in the chronic phase (25). For example, at a spinal level, sustained neuropeptide signaling and inflammatory mediators induce persistent central sensitization, 
which could contribute to the chronicization of pain symptoms $(26,27)$.

It is noteworthy that cutaneous innervation seems affected even in type-1 CRPS (no nerve lesion) as reflected by lower axonal density (28), lower C-fiber and A $\delta$-fiber density, and changes in hair follicles and sweat glands innervation (29). In that vein, it was suggested that a minimal distal nerve injury (not detectable) could be the initial trigger for the cascade of events leading to CRPS $(16,28)$, thus likely explaining why some people do not recall any inciting trauma of their CRPS.

\section{Dysregulation of the Autonomic Nervous System}

CRPS has been considered for a long time as hyperactivity of the autonomic nervous system. This was because of the changes in skin color, temperature, and sweating, and because people were diagnosed with CRPS, only if symptoms were reduced by a stellate ganglion block or by a sympathetic block of the lumbar chain $(1,5,30)$. Whether the autonomic nervous system is involved in CRPS pathophysiology is controversial, some authors have reported sympathetic dysfunction in the acute phase and its normalization over 3 months $(31,32)$, others reported a normal activity or an increase $(1,33-35)$. This warrants studies on that topic because dysregulation of the autonomic nervous system may at least contribute to state changes (warm vs. cold limb) that cannot be only due to local inflammation $(30,36)$.

\section{Immune Dysfunction}

In the last decade, research has revealed that antibodies (e.g., of adrenergic and cholinergic receptors) could be present in the serum samples of people with CRPS. This suggests that the immune system could contribute to CRPS chronicization (3739). Research in this field is booming and the upcoming evidence ought to be considered in future reviews.

\section{UNDERSTANDING BRAIN CHANGES IN CRPS}

This section deals with the neuronal maladaptive plasticity reported in CRPS and the neuroanatomical and functional changes studied by neuroimaging techniques and transcranial magnetic stimulation (TMS), respectively. Most changes in CRPS are presented in Table 2 and are illustrated in Figure 1.

\section{Neuronal Maladaptive Plasticity and Relation to NMDA Receptors}

Neuronal plasticity is the capacity of neurons to modulate the efficacy of their synaptic connections with other elements of the CNS (neurons, glial cells). Long-term potentiation (LTP) and long-term depression (LTD) characterize, respectively, the increase and the decrease of synaptic strength. LTP and LTD act via, e.g., isotopic receptors of glutaminergic $N$-methyl-Daspartate (NMDA), which works as gates for massive inflows of calcium ions in the post-synaptic neuron when previously depolarized (70). The duration of these changes (LTP or LTD) can be influenced by some neuromodulators, such as dopamine,
TABLE 2 | Brain changes reported in CRPS.

Changes of volumes and maps (decrease $\downarrow$ or increase $\uparrow$ )

$\downarrow$ Gray matter volume in right anterior insula, OFC, right ventral PFC, CC, inferior PL, SMA, nucleus accumbens, putamen (40-43)

$\uparrow$ Gray matter volume in the M1 contralateral to CRPS hand, dorso-medial PFC, right hypothalamus, bilateral dorsal putamen, choroid plexus $(42,44)$

$=$ or $\downarrow$ Extent of CRPS hand maps in the contralateral S1 and in M1 (18, 45-51)

$\uparrow$ Shifting of CRPS hand map in the contralateral S1 (18)

Changes of connectivity, activation, metabolism

Alteration or decrease $(\downarrow)$ or no change (=)

$\downarrow$ Default mode network (52-54)

$\downarrow$ Connectivity to sensorimotor cortices (41)

$\downarrow$ Metabolism in the M1 and dorsal PFC (55)

$\downarrow$ Connectivity between M1 and SPL in the hemisphere contralateral to CRPS

side (41)

$\downarrow$ Connectivity between ventro-medial PFC and basal ganglia (40)

$\downarrow$ Thalamic perfusion $(56,57)$

$\downarrow$ Connectivity between putamen and cerebellum (43)

$\downarrow$ Opercular activation during painful stimulation (58)

$\downarrow$ Pain and sensory threshold via sensitization of $N$-methyl-D-aspartate

(glutamate) receptors (59)

Increase $(\uparrow)$ or no change $(=)$

$\uparrow$ Activation of M1 and SMA during movement (60)

$\uparrow$ Activation of M1 and SMA at rest (41)

$\uparrow$ Metabolism bilaterally in S2, mid-anterior and posterior CC, PC, PPC, cerebellum, right posterior insula, and thalamus (55)

$=$ or $\uparrow$ Amplitude and frequency of SSEP in the contralateral S1 hand area in response to stimulation on the CRPS side $(45,49)$

$\downarrow$ Suppression of SSEP by paired-evoked paradigm bilaterally $(61,62)$

$=$ Peak latency of SSEP $(18,46,48,49)$

$=$ Peak strength of SSEP $(46,62)$

$\uparrow$ Connectivity between ventro-medial PFC and insula (40)

$\uparrow$ Connectivity between putamen and pre-post-central gyri (43)

$\uparrow$ Activation of PPC during painful stimulation (58)

Changes of Neurophysiological Outcomes (decrease $\downarrow$ or no change $=$ or increase $\uparrow$ )

$\downarrow$ Reactivity of M1-related $20-\mathrm{Hz}$ rhythm to tactile stimulation $(49,63)$

$\downarrow \operatorname{SICI}(23,50,64)$

$\downarrow$ LAI (65)

$=\operatorname{SAl}(65,66)$

$=$ PAS (65)

$=$ Cortical silent period $(65,67)$

$=\operatorname{RMT}(64,65,68,69)$

$=$ or $\downarrow$ MEP amplitude $(64,65,67-69)$

$=$ or $\uparrow \operatorname{ICF}(64,65)$

$\uparrow$ I-wave facilitation (23)

Acronyms of neurophysiological outcomes. SICl, short-interval intracortical inhibition; LAl, SAl, long-/short-afferent inhibition; PAS, paired associative stimulation; RMT, resting motor threshold; ICF, intracortical facilitation; I-wave, indirect wave corresponding to indirect activation of corticospinal cells (at the cell body, not directly at the axons) by transcranial magnetic stimulation.

Acronyms for structures. OFC, orbitofrontal cortex; PFC, prefrontal cortex; CC, cingulate cortex; PL, parietal lobule; SMA, supplementary motor area; M1, S1, primary motor and somatosensory cortex, respectively; SPL, superior parietal lobe; S2, secondary somatosensory cortex; PC, parietal cortex; PPC, post-parietal cortex; SSEP, somatosensory-evoked potential. 


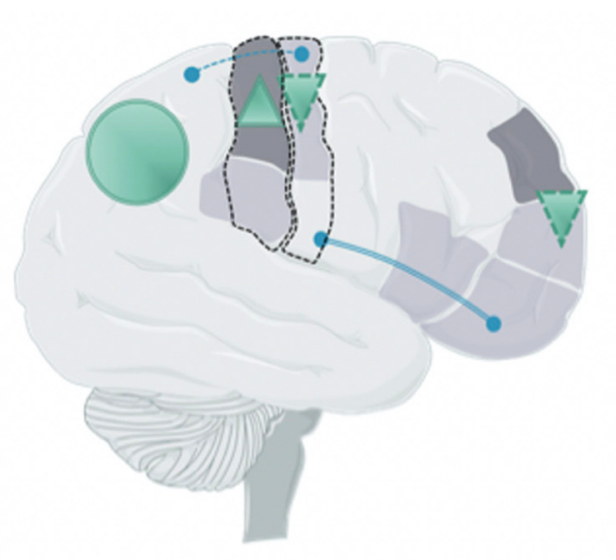

Grey matter volume increase

- Connectivity increase

Activation increase

Alteration of cortical hand maps

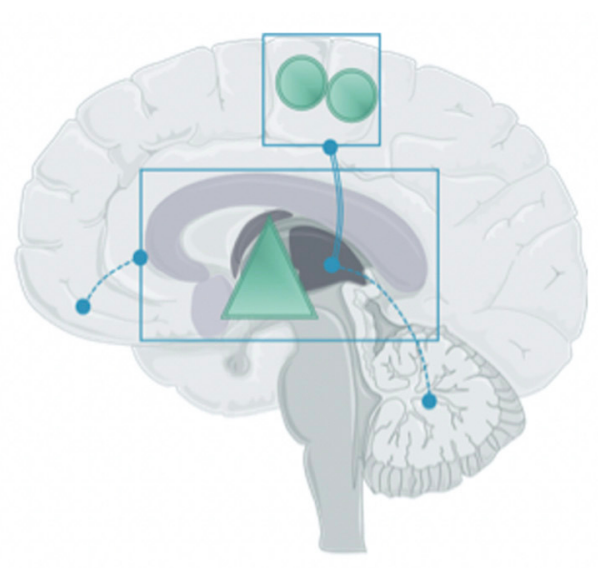

Grey matter volume decrease

--- Connectivity decrease

Metabolism increase

Metabolism decrease

FIGURE 1 | Brain changes in people with a complex regional pain syndrome. This figure illustrates the main data reported in Table 2 owing to the increase or decrease of gray matter volume, connectivity, activity, and metabolism and the alteration of maps related to hand sensorimotor function.

serotonin, acetylcholine, norepinephrine (71-73). That is, the more often synaptic circuits are used, the higher will be the LTP. Thus, the more often pain pathways are activated, the lower will be the threshold to trigger pain messages. In chronic pain, the NMDA receptors lead to the activation of sensory and nociceptive pathways at a lower threshold of peripheral stimuli (a change referred to as "central sensitization") (74). In CRPS, some studies showed positive results after the administration of an NMDA-antagonist, such as ketamine, either alone (75-77) or in combination with other medications (78). This explains why it was suggested that glutamate NMDA receptors could play a pivotal role in brain maladaptive plasticity in CRPS (59).

\section{Neuroimaging Studies of Brain Volumes, Activation, and Connectivity Brain Volumes}

Changes in CRPS include a decrease in the gray matter volume in the right anterior insula, orbitofrontal cortex (OFC), right ventromedial prefrontal cortex (PFC), cingulate cortex, putamen, sensorimotor cortices, and parietal areas (40-43), and an increase in the gray matter volume in the two dorsal putamen, right hypothalamus, dorsomedial PFC, contralateral primary motor cortex, and choroid plexus $(42,44)$.

\section{Primary Somatosensory Cortex (S1)}

Except in one study (45), most magnetoencephalography (MEG), electroencephalography (EEG), or functional MRI (fMRI) data in CRPS confirmed a significant shrinking of S1 hand representation in the hemisphere contralateral to the painful side, as compared to the unaffected hand or pain-free subjects
$(18,46-50)$. One study denoted that the center of gravity of the S1 hand area was shifted to the lip area (18). EEGrecorded amplitudes of somatosensory evoked potentials (SSEPs) following median/ulnar nerve stimulation on the CRPS side showed that the S1 hand area was more responsive to peripheral signal than on the unaffected side or in pain-free people (49), i.e., hyperexcitability but without any change of peak timing $(18,46,48,49)$. Some fMRI studies reported a smaller activation and weaker blood-oxygen level-dependent signal (BOLD) in the CRPS-related S1 area as compared with the other side $(46,79)$ or to pain-free subjects $(80)$, but one study did not find any between-hemisphere difference (58). Somatosensory excitability was assessed by SSEP using the paired-pulse evoked suppression paradigm. This technique requires the application of two asynchronous stimulations of the median nerve at the level of the wrist, with the expectation that the amplitude of the second SSEP in S1 is significantly smaller than the first. Results showed a marked bilateral reduction of cortical disinhibition in specific tasks, as compared with that of pain-free subjects, thus supporting the dysfunction of somatosensory circuits $(61,62)$.

\section{Motor Areas}

The activation of the primary motor cortex (M1) and supplementary motor area (SMA) recorded by fMRI during finger tapping with the CRPS-affected limb was shown to be increased bilaterally but more markedly on the ipsilateral side (60). The technique of arterial spin labeling was used to test the motor-resting neural activity and it was found that blood perfusion in M1 and the SMA was increased in people with chronic CRPS (41). Also, the technique of positron emission 
tomography with F-fluorodeoxyglucose (FDG-PET) tested that the metabolism of M1 and dorsal PFC contralateral to the CRPSaffected side was decreased as compared to that in pain-free people (55). Two MEG studies investigated the $20 \mathrm{~Hz}$ rebound of $\mathrm{M} 1$ in response to somatosensory stimulation, which reflects the increase of M1 excitability after a period of suppressed activity due to the somatosensory stimulation. In people with CRPS, 20$\mathrm{Hz}$ oscillations did not adapt properly in response to tactile (49) and noxious (63) stimuli, thus suggesting the alteration of M1 inhibition processes.

\section{Non-motor Areas}

fMRI recordings during painful stimulation in people with CRPS denoted an increase (either contralateral to the site of stimulation or bilateral) of the responses in the posterior cingulate cortex, in parallel with a decrease of the posterior opercular cortex (58). Several studies found a bilateral increase of the responses in somatosensory cortices, cingulate cortex, parietal cortex, cerebellum, as well as in the right insula and the right thalamus (55). Perfusion was also decreased in the part of the thalamus contralateral to the affected limb $(56,57)$.

\section{Inter-structure Connectivity}

Diffusion-tensor imaging (a technique using MRI-recorded direction of water within the myelinated fibers to reconstruct brain tractography) helped detect the increase of connectivity between the ventromedial PFC and insula, and between the putamen and pre-/post-central gyri (43) and the decrease of connectivity between the ventromedial PFC and basal ganglia (40) and between putamen and cerebellum (43). Precisely, the involvement of the basal ganglia in the physiopathology of CRPS was recently hypothesized (81). In support, it was shown that basal ganglia activation to nociceptive stimuli was increased in children $(82,83)$ and adults with CRPS (58) and that the functional linking between the intraparietal sulcus and caudate nuclei was bilaterally altered in people with CRPS (52). Restingstate fMRI studies also brought about evidence of the alteration of the default mode network in CRPS (52-54).

\section{TMS Studies of Brain Functional Integrity}

Transcranial magnetic stimulation is a reliable tool widely used to study M1 mapping and to characterize markers of M1 and corticospinal excitability in CRPS (84). Some TMS outcomes were reported to be different in CRPS and others unchanged as compared to pain-free people.

\section{Cortical Organization}

Mapping of M1 representation by single-pulse TMS in people with type-1 CRPS showed that the affected hand had a smaller M1 representation than the unaffected with a center of gravity more variable but not significantly different between sides or compared with that in pain-free people (51).

\section{M1 Inhibition}

TMS paradigms enable investigation of the different mechanisms of M1 inhibition, and CRPS studies showed that some inhibitory processes could be altered and others not. Paired-pulse TMS of M1 at inter-stimulus intervals below $4 \mathrm{~ms}$ showed that the short-interval intracortical motor inhibition (SICI, depending on $\mathrm{GABA}_{\mathrm{A}}$ receptors activity) (85) was reduced either in both the hemispheres as compared to that in pain-free individuals $(64,68)$ or only in M1 contralateral to CRSP side $(23,50,86)$. Of note, the cortical silent period following a motor-evoked potential (MEP) (superimposed on background isometric contraction) is a different mechanism of M1 inhibition that depends on the $\mathrm{GABA}_{\mathrm{B}}$-receptors, and which was shown to be comparable between sides in CRPS and to pain-free subjects $(65,67)$. Also, the long-afferent inhibition (LAI), which investigates sensorimotor integration, i.e., the inhibition of TMS-MEP by sensory afferents volley triggered by electrical stimulation of a peripheral nerve (85), was shown to be reduced in M1 contralateral to the affected hand (65). However, at shorter inter-stimulus intervals aiming at testing the short-afferent inhibition (SAI), the MEP reduction by median nerve stimulation was unchanged as compared to that in pain-free subjects $(65,66)$. In addition, the paired associative stimulation (PAS), e.g., 180 pairs of nerve electric stimulation and TMS of M1, induced the same sensorimotor plasticity (MEP increase) in CRPS as in pain-free subjects (65). Thus, circuits connecting S1 and M1 seem to work properly in CRPS and may not explain the differences in M1 inhibitory function and plasticity.

\section{M1 Facilitation}

TMS studies showed controversial findings in CRPS for M1 facilitation. Indeed, paired-pulse TMS of M1 at inter-stimulus intervals over $10 \mathrm{~ms}$ showed that the intracortical motor facilitation (ICF, depending on NMDA glutamatergic receptors) could be comparable between sides and to that in pain-free subjects (64) and significantly increased in the hemisphere contralateral to the CRPS side (65).

\section{M1 and Corticospinal Excitability}

Among other TMS outcomes in CRPS that were unchanged between hemispheres or as compared to pain-free people are the resting motor threshold (RMT) and the amplitude of the MEP tested at $120 \% \operatorname{RMT}(64,65,68,69)$. RMT is the minimal TMS intensity required to evoke five MEP $\geq 50 \mu \mathrm{V}$ out of 10 successive trials in the target muscle at rest and it informs on the basic transsynaptic M1 excitability. The MEP amplitude informs on the corticospinal excitability and it depends on the volume of M1 tissue responding to TMS and on the synchronicity of descending volleys to excite the alpha-motoneurons in the spinal cord. Of note, the same authors showed that MEP amplitudes were either unchanged in CRPS (68) and bilaterally decreased (67) as compared to those in pain-free subjects (refer to Table 2).

\section{Clinical Significance of Brain Changes}

Brain changes in CRPS are extensive and they underlie multiple brain areas, and maladaptive neuronal plasticity has been evidenced as a primary cause of chronicization $(17,87)$. Pain intensity was reported to be positively correlated with volume changes of the left posterior hippocampus and left amygdala (42) and negatively correlated with volume changes of the bilateral dorsolateral PFC, putamen, and other areas associated with pain processing (41-43). Also, the shrinkage of hand S1 
representation increased with the intensity of pain and the presence of hyperalgesia (88) and the motor threshold of the M1 hand area was significantly lower (higher M1 excitability) in the presence of allodynia (68). Most importantly, some abnormal brain changes were found to be reversed, even normalized, concomitantly to the improvement of symptoms and CRPS resolution $(17,88,89)$. CRPS chronicization being related to maladaptive brain changes, it is thus legitimate to propose that improvement of the condition in individuals depends on the normalization of these brain changes.

\section{ARE TREATMENTS ADAPTED TO BRAIN CHANGES IN CRPS?}

The previous sections deciphered that neuroanatomical and functional brain modifications in CRPS can be of clinical significance and rely on the somatosensory, motor, and emotional pathways, in one or both hemispheres (refer to Table 2). Data are, however, sometimes controversial, likely due to the fact that some studies tested the acute stage, whereas others the chronic. Also, the clinical significance of brain changes remains unclear, i.e., whether they are specific to CRPS symptoms or shared with other chronic pain conditions. Thus, it is not known whether a conventional treatment that reduces a symptom influences brain maladaptive plasticity, and in other words, whether a treatment actually heals the cause or the consequence. In the latter case, improvement of the condition may only be transient, and the condition will not be resolved due to the persistence of abnormal brain functioning.

The conventional care and follow-up of CRPS are multidisciplinary with pharmacological interventions (often a combination of molecules) (90), local anesthetic sympathetic blockade (91-93), ketamine injections (75, 76, 94, 95), physical or occupational therapy $(96,97)$, and psychological support $(13,98)$. However, there is almost no clinical evidence to support these treatments $(10,90,99)$, being CRPS often refractory to any intervention. Also, there is no randomized clinical trial published yet to defend the multidisciplinary approach. Overall, CRPS literature remains scarce on a treatment influencing brain plasticity with clinical significance. Conventional treatments that influence sensory integration, such as rehabilitation, may be sometimes of concern because they are based on intensive movement training but people with CRPS can feel pain only by the thoughts of moving the painful part $(100,101)$, thus creating additional discomfort that could even worsen brain changes. The question is thus whether conventional treatments in CRPS are appropriate and sufficient to normalize brain changes and improve the condition sustainably. For example, S1 and M1 map distortion in CRPS can alter sensorimotor integration as already shown in other pain conditions (e.g., phantom limb pain) (16): people with CRPS take a longer time to recognize the laterality of their affected hand (102) and this leads to a mismatch between sensory information and movement, thus hindering motor control and generating pain. Only an approach nurturing the brain with sensory information from the affected side, to improve sensorimotor control and without creating pain, could contribute to normalize S1 and M1 neuroplasticity and decrease CRPS severity. This has never been addressed by studies using conventional treatment regimens.

The way CRPS is treated should be revisited. Researchers should test the approaches that influence sufficiently the neuroplasticity at the origin of the improvement of the condition. The next section deals with the potential and current evidence of non-invasive neurostimulation to normalize maladaptive brain changes. It is noteworthy, however, that one size does not fit all, i.e., people experience pain differently and respond to treatment differently, thus the same treatment may not be efficient for everyone. It is suggested that individualized protocols of neurostimulation should be developed on the basis of individual brain changes in CRPS.

\section{NON-INVASIVE NEUROSTIMULATION IN CRPS}

The use of non-invasive neurostimulation techniques for the management of pain is based on its potential to influence the neuronal plasticity related to the condition (brain changes exposed in the previous sections). These techniques include cortical and peripheral repetitive transcranial magnetic stimulation [rTMS, repetitive peripheral magnetic stimulation (rPMS)], transcranial direct current stimulation (tDCS), and transcutaneous electrical nerve stimulation (TENS). This section presents the rationale for plasticity and the different techniques of non-invasive neurostimulation, the current evidence in the CRPS, and proposes research and clinical prospective.

\section{Brain Plasticity Influenced by Non-invasive Neurostimulation}

Non-invasive neurostimulation can influence cerebral plasticity and reverse maladaptive neural changes either directly by brain stimulation or indirectly via ascending pathways following peripheral stimulation of nerves, muscles, or spinal cord $(72,103-106)$. These techniques can be potentially implemented into interdisciplinary approaches that are precisely aimed at promoting the central reorganization at the origin of pain reduction. Compared to other invasive treatments, neurostimulation techniques offer multiple advantages. They are painless, particularly with the use of magnetic stimulation (rTMS, rPMS), and do not have side effects (or limited ones such as transient headaches for rTMS and tDCS). Especially, they can be used as add-ons to rehabilitation exercises. Indeed, neurostimulation can normalize the maladaptive brain plasticity responsible for CRPS chronicization, and this influence on plasticity primes and potentiates the effects of the task-oriented rehabilitation, thus making it possible to go beyond the gains already reached and plateaued (107). It is known, furthermore, that patients with CRPS often experience kinesiophobia or fear of movement (101). This said, rPMS of muscles that mimic the contraction/relaxation mechanisms and triggers movements of the CRPS limb with any pain could help reduce kinesiophobia and all the psychological stress surrounding the attempt to move, 
thus easing at the end the compliance to therapy and its success $(106,107)$.

\section{The Different Techniques Cortical and Peripheral Repetitive Magnetic Stimulation (rTMS, rPMS)}

Repetitive magnetic stimulation consists of the administration of painless magnetic pulse trains above the brain, e.g., M1 or dorsal PFC (rTMS, T for transcranial), or at the periphery, e.g., over nerve or muscle (rPMS, P for peripheral). The manipulation of the stimulation parameters, such as the frequency (from 0.1 up to $50 \mathrm{~Hz}$ ), train duration, inter-train interval, coil positioning over a cortical or peripheral target, enables modifying of the actual net after-effects in the neural tissues beneath the coil, i.e., depolarization or hyperpolarization/depression [for details, refer to Pell et al. (73), Beaulieu and Schneider (108)]. In clinical pain studies, rTMS is usually applied over M1 at subthreshold intensity (below the intensity eliciting a muscle response via the corticospinal pathway). The after-effects (LTP-like excitation or LTD-like inhibition) can last from minutes to several hours, depending on the protocol and the task tested and can induce changes of excitability and function in remote areas. Longlasting rTMS-induced analgesic effects likely rely on LTP/LTDlike mechanisms (refer to the previous section on central sensitization) via an influence on glutamatergic networks (109).

rPMS is commonly applied over a spinal root, nerve, or muscle belly at a suprathreshold intensity to trigger muscle contraction (72). It is hypothesized that it may recruit proprioceptive afferents directly by the depolarization of sensory fibers terminals and indirectly via the induction of repeated contractions and joint movements (108). Also, due to minimal recruitment of nociceptive receptors (the magnetic pulse bypasses skin without resistance), it is painless and the proprioceptive message mediated to the brain is not contaminated by cutaneous information. Thus, rPMS mimics the contraction/relaxation process of one muscle or a group of muscles, and the pure proprioceptive information generated is coherent with the appropriate motor control to influence sensorimotor plasticity at the origin of motor improvement or pain reduction (108). In support, it is shown in motor disorders or in chronic pain that rPMS influences the cortical markers with clinical significance (110).

\section{Transcranial Direct Current Stimulation}

tDCS is administrated by means of two electrodes (the anode and the cathode) fixed on the scalp. Many studies have shown a greater reduction of pain when the anode is positioned above M1, as compared to S1 or the dorsolateral PFC (111, 112). The cathode is always on the forehead, supraorbital area, contralateral to M1 stimulated. M1 stimulation by tDCS may activate corticospinal and corticothalamic projections which in turn influence the activity of regions of the diencephalon, brain stem, and spinal cord involved in pain modulation mechanisms $(113,114)$. Specifically, studies show that the effectiveness of tDCS in relieving chronic pain and maintaining effects depends on key stimulation parameters, such as electrode position (anodal
M1 montage), stimulation intensity (2 $\mathrm{mA})$, duration (20 min), and the number of weekly sessions $(111,112)$.

\section{Transcutaneous Electrical Nerve Stimulation}

TENS can be applied at a high frequency $(\mathrm{HF}>50 \mathrm{~Hz})$ with subthreshold intensity (no muscle contraction) or at a low frequency $(\mathrm{LF}<10 \mathrm{~Hz})$ with suprathreshold intensity (producing muscle contraction) (115). In humans, both protocols can reduce chronic pain by the generation of somatosensory inputs but their respective mechanisms of action seem different owing to different after-effects due to different frequencies used (116). Also, lowintensity conventional TENS can have maximal analgesic effects homotopically, i.e., on the stimulated side, whereas high-intensity TENS can induce spatially diffused analgesic effects. It has also been shown that only high-intensity TENS produced long-lasting changes in S1 and M1 areas and in their connectivity to vmPFC, which is part of the pain inhibition descending system (116). This activation of the pain inhibition systems promotes the release of endogenous opioids, thus explaining the diffuse analgesic effects (117-119).

\section{Current Evidence in CRPS}

Fourteen studies have been published to date on the use of noninvasive neurostimulation in CRPS, either alone, or combined with other therapies. Table 3 details these rTMS, tDCS, rPMS, and TENS studies.

\section{rTMS}

Three studies tested the after-effects of rTMS in people with CRPS: two studies focused on type I (128) and the third on mixed types I and II CRPS (122). All the three administrated rTMS over M1 were contralateral to the CRPS hand. The first two studies used $10 \mathrm{~Hz}$ rTMS in a single session with 10 patients or 10 sessions with 12 patients, one time a day for 10 days in a row $(46,128)$. Precisely, Pleger et al. (128) reported that pain intensity could be reduced after one rTMS session (as measured on the visual analog scale or VAS), as compared to sham stimulation, with the VAS scores being the lowest at $15 \mathrm{~min}$ after the end stimulation, but back to baseline at $45 \mathrm{~min}$. One study (127) applied rTMS as an add-on intervention of a standard pharmacological and rehabilitation treatment for 10 consecutive sessions (10 days in a row). Of note, the pharmacological and rehabilitation treatment was first administrated over a month before adding on rTMS. The authors reported a reduction of pain (scores of VAS and McGill Pain Questionnaire or MPQ) and improvements of affective and emotional scores (SF-36 and Hamilton Depression Scale) during the period of rTMS treatment, but the effects had vanished at follow-ups of 1 week and 3 months. The third study (122) was conducted in a mixed cohort (CRPS types I and II). The authors used an open-label and non-randomized design to investigate the aftereffects of the priming of $10 \mathrm{~Hz}$ rTMS by intermittent theta burst stimulation (iTBS). The protocol of iTBS ( $5 \mathrm{~Hz}$ bursts of three pulses delivered at $50 \mathrm{~Hz}$ ) was delivered at an intensity of $70 \%$ of the RMT and was followed immediately by the $10 \mathrm{~Hz}$ rTMS (10 s trains with $30 \mathrm{~s}$ inter-train interval) delivered at $80 \%$ RMT with the coil guided by real-time neuronavigation. A decrease in 
TABLE 3 | Studies with noninvasive neurostimulation in CRPS

\begin{tabular}{|c|c|c|c|c|c|c|c|c|c|}
\hline \multirow[t]{2}{*}{ References } & \multirow[t]{2}{*}{ Study type } & \multirow[t]{2}{*}{ Population } & \multicolumn{7}{|c|}{ Intervention } \\
\hline & & & Stimulation protocol & Control & Number of sessions & Site & Parameters & $\begin{array}{l}\text { Scales and time of } \\
\text { testing }\end{array}$ & Outcomes reported \\
\hline Bilgili et al. (120) & $\begin{array}{l}\text { Double-blinded, } \\
\text { placebo-controlled, } \\
\text { randomized trial }\end{array}$ & $\begin{array}{l}\text { CRPS type I }(N=30) \\
\text { Exp }=15 \\
\text { Sham }=15\end{array}$ & $\begin{array}{l}\text { TENS + standard } \\
\text { physical therapy }\end{array}$ & $\begin{array}{l}\text { Sham stimulation + } \\
\text { standard physical } \\
\text { therapy }\end{array}$ & $\begin{array}{l}15 \text { Sessions, } \\
\text { frequency/week not } \\
\text { reported }\end{array}$ & $\begin{array}{l}\text { Active electrode on the } \\
\text { dorsal aspect of the } \\
\text { forearm, passive } \\
\text { electrode on the dorsal } \\
\text { aspect of hand }\end{array}$ & $\begin{array}{l}\text { 100-Hz TENS } \\
\text { (50-100 ms pulse } \\
\text { duration) at intensity } \\
\text { below the discomfort } \\
\text { threshold, } 20 \mathrm{~min}\end{array}$ & $\begin{array}{l}\text { VAS, LANSS, DN-4, } \\
\text { ROM, edema size, } \\
\text { functional capacity with } \\
\text { hand dynamometer and } \\
\text { DHI }\end{array}$ & $\begin{array}{l}\text { Reduction of pain, } \\
\text { edema, and fingers } \\
\text { ROM }\end{array}$ \\
\hline $\begin{array}{l}\text { Bodenheim and } \\
\text { Bennett (121) }\end{array}$ & Case report & $\mathrm{SA} \operatorname{Exp}=1$ & TENS & na & $\begin{array}{l}24 \text { Sessions (3 } \\
\text { sessions/week, } 8 \\
\text { weeks) }\end{array}$ & Acupuncture points & $\begin{array}{l}20-\mathrm{Hz} \text { TENS at intensity } \\
\text { adjusted to patient } \\
\text { tolerance }(100-\mu \mathrm{s} \text { pulse } \\
\text { width), } 60 \mathrm{~min}\end{array}$ & $\begin{array}{l}\text { Clinical evaluation of pain } \\
\text { and physical outcomes }\end{array}$ & $\begin{array}{l}\text { Reduction of pain, } \\
\text { recovery of ankle } \\
\text { ROM, increase of } \\
\text { bone stock, and } \\
\text { reversal of atrophy }\end{array}$ \\
\hline $\begin{array}{l}\text { Gaertner et al. } \\
\text { (122) }\end{array}$ & $\begin{array}{l}\text { Open-label and } \\
\text { non-randomized study }\end{array}$ & $\begin{array}{l}\text { CRPS type I and II }(N=21) \\
\operatorname{Exp}=6 \\
\operatorname{Exp}=15\end{array}$ & $\begin{array}{l}\text { ITBS + rTMS iTBS + } \\
\text { rTMS }\end{array}$ & na na & $\begin{array}{l}1 \text { Session } 5 \text { Sessions (1 } \\
\text { session/day, } 5 \text { days) }\end{array}$ & $\begin{array}{l}\text { Contralateral M1 } \\
\text { Contralateral M1 }\end{array}$ & $\begin{array}{l}\text { iTBS at } 70 \% \text { RMT (5-Hz } \\
\text { bursts of } 3 \text { pulses at } \\
50 \mathrm{~Hz}, 2 \mathrm{~s} \text { ON/8 } \mathrm{s} \text { OFF, } \\
\text { total }=600 \text { pulses) } \\
\text { followed immediately by } \\
10-\mathrm{Hz} \text { rTMS at } 80 \% \\
\text { RMT (10-s trains, } 30-\mathrm{s} \\
\text { inter-train interval; total } \\
=2,000 \text { pulses). Total = } \\
2,600 \text { pulses } \\
\text { per session }\end{array}$ & $\begin{array}{l}\text { VAS, at baseline, then } \\
\text { after the single or the } 5 \\
\text { sessions and } 2 \text { weeks } \\
\text { after }\end{array}$ & $\begin{array}{l}\text { Significant pain } \\
\text { reduction after } 1 \\
\text { session and 1-week } \\
\text { post-treatment; } \\
\text { however, no group } \\
\text { differences were } \\
\text { present }\end{array}$ \\
\hline Houde et al. (123) & Case report & $\begin{array}{l}\text { CRPS type I } \\
\text { Exp }=1\end{array}$ & $\begin{array}{l}\text { Anodal tDCS Anodal } \\
\text { tDCS + TENS }\end{array}$ & na na & $\begin{array}{l}5 \text { Sessions ( } 1 \\
\text { session/day, } 5 \text { days) } 10 \\
\text { Sessions (1 } \\
\text { session/day, } 5 \text { days, } \\
\text { repeated after } 6 \\
\text { months) }\end{array}$ & $\begin{array}{l}\text { tDCS on contralateral } \\
\text { M1, TENS over painful } \\
\text { area }\end{array}$ & $\begin{array}{l}\text { 2-mA tDCS and 3-Hz } \\
\text { TENS ( } 400 \mu \mathrm{s}), 25 \mathrm{~min}\end{array}$ & $\begin{array}{l}\text { VAS; at baseline, after } \\
15 \text { min of each } \\
\text { intervention, after } 6 \\
\text { months from tDCS + } \\
\text { TENS only }\end{array}$ & $\begin{array}{l}\text { tDCS + TENS slightly } \\
\text { reduced pain intensity } \\
\text { and unpleasantness }\end{array}$ \\
\hline Kesler et al. (124) & Cohort study & $\begin{array}{l}\operatorname{RSD}(N=10) \\
\operatorname{Exp}=10\end{array}$ & $\begin{array}{l}\text { TENS + home-based } \\
\text { physical therapy }\end{array}$ & na & $\begin{array}{l}\text { Various depending on } \\
\text { the patient (4 } \\
\text { sessions/day, multiple } \\
\text { days) }\end{array}$ & $\begin{array}{l}\text { Over vascular supply of } \\
\text { affected extremity }\end{array}$ & $\begin{array}{l}\text { Intensity adjusted to } \\
\text { comfort, } 60 \mathrm{~min} \text {. No } \\
\text { other information } \\
\text { provided }\end{array}$ & $\begin{array}{l}\text { Clinical evaluation of pain } \\
\text { and physical outcomes }\end{array}$ & $\begin{array}{l}N=7 \text { with complete } \\
\text { remission within } 2 \\
\text { months }\end{array}$ \\
\hline Krause et al. (67) & Cohort study & $\begin{array}{l}\text { CRPS type I }(N=22) \\
\text { Exp }=12 \\
\text { Control }=10\end{array}$ & rPMS & Healthy subjects & 1 Session & Over C7/C8 & $\begin{array}{l}20-\mathrm{Hz} \text { rPMS at } 120 \% \\
\mathrm{RMT}, 10 \text { trains of } 10 \mathrm{~s} \\
\text { each, inter-train interval } \\
\text { not reported; Total = } \\
2,000 \text { pulses over } \\
\sim 10 \mathrm{~min}\end{array}$ & $\begin{array}{l}\text { Cortical and spinal MEP, } \\
\text { contra-and-ipsilateral } \\
\text { cortical silent period; } \\
\text { pre-/post-rPMS testing }\end{array}$ & $\begin{array}{l}\text { Less effective input to } \\
\text { the motor cortical } \\
\text { system }\end{array}$ \\
\hline $\begin{array}{l}\text { Lagueux et al. } \\
\text { (125) }\end{array}$ & $\begin{array}{l}\text { Randomized parallel single } \\
\text { blind study }\end{array}$ & $\begin{array}{l}\text { CRPS type I }(N=22) \\
\text { Exp }=11 \\
\text { Control }=11\end{array}$ & $\begin{array}{l}\text { Anodal tDCS + graded } \\
\text { motor imagery }\end{array}$ & $\begin{array}{l}\text { Sham stimulation + } \\
\text { graded motor } \\
\text { imagery }\end{array}$ & $\begin{array}{l}14 \text { Sessions (1 } \\
\text { session/day, } 5 \\
\text { days/week for } 2 \text { weeks, } \\
1 \text { day/week for } 4 \text { weeks) }\end{array}$ & Contralateral M1 & $2-m A$ tDCS of $20 \mathrm{~min}$ & $\begin{array}{l}\text { Pain perception, quality } \\
\text { of life, kinesiophobia, } \\
\text { pain catastrophizing, } \\
\text { anxiety, mood; at } \\
\text { baseline, at } 6 \text { weeks of } \\
\text { treatment and } 1 \text { month } \\
\text { after the end of treatment }\end{array}$ & $\begin{array}{l}\text { No added value of } \\
\text { tDCS combined with } \\
\text { GMI for reducing pain }\end{array}$ \\
\hline Leo (126) & Case report & RSD $\operatorname{Exp}=1$ & TENS & na & $\begin{array}{l}2 \text { Sessions ( } 1 \\
\text { session/day, } 22 \text { days } \\
\text { apart) }\end{array}$ & $\begin{array}{l}\text { Bilaterally at } \\
\text { acupuncture points }\end{array}$ & $\begin{array}{l}\text { 4-Hz TENS at intensity } \\
\text { below pain threshold, } \\
30 \text { s for each point }\end{array}$ & $\begin{array}{l}\text { Pain and right upper } \\
\text { extremity ROM; at } \\
\text { baseline and after each } \\
\text { session }\end{array}$ & $\begin{array}{l}\text { Reduction of pain and } \\
\text { increased ROM at } \\
\text { painful, improvements } \\
\text { still present at } 3 \\
\text { months }\end{array}$ \\
\hline
\end{tabular}


TABLE 3 | Continued

\begin{tabular}{|c|c|c|c|c|c|c|c|c|c|}
\hline \multirow[t]{2}{*}{ References } & \multirow[t]{2}{*}{ Study type } & \multirow[t]{2}{*}{ Population } & \multicolumn{7}{|c|}{ Intervention } \\
\hline & & & Stimulation protocol & Control & Number of sessions & Site & Parameters & $\begin{array}{l}\text { Scales and time of } \\
\text { testing }\end{array}$ & Outcomes reported \\
\hline Picarelli et al. (127) & $\begin{array}{l}\text { Double-blind, } \\
\text { placebo-controlled, } \\
\text { two-arm, randomized trial }\end{array}$ & $\begin{array}{l}\text { CRPS type I }(N=23) \\
\text { Exp }=12 \\
\text { Sham }=11\end{array}$ & $\begin{array}{l}\text { rTMS + best medical } \\
\text { treatment }\end{array}$ & Sham stimulation & $\begin{array}{l}10 \text { Sessions (1 } \\
\text { session/day, } 5 \\
\text { days/week, } 2 \text { weeks) }\end{array}$ & Contralateral M1 & $\begin{array}{l}\text { 10-Hz rTMS at } 100 \% \\
\text { RMT; } 25 \text { trains of } 10 \mathrm{~s} \\
\text { each, } 60 \text {-s inter-train } \\
\text { interval; total }=2,500 \\
\text { pulses over } \sim 29 \mathrm{~min}\end{array}$ & $\begin{array}{l}\text { VAS, MPQ, SF- } 36 \text {, } \\
\text { HDRS; at baseline, then } \\
\text { daily during the } 10 \\
\text { sessions and } 1 \text { week/3 } \\
\text { months after the last } \\
\text { session }\end{array}$ & $\begin{array}{l}\text { Reduction of pain and } \\
\text { improvement of } \\
\text { affective aspects only } \\
\text { during the period of } \\
\text { stimulation }\end{array}$ \\
\hline Pleger et al. (128) & Cohort study & $\begin{array}{l}\text { CRPS type I } \\
\text { Exp }=10\end{array}$ & rTMS & Sham stimulation & 1 Session & Contralateral M1 & $\begin{array}{l}\text { 10-Hz rTMS at } 110 \% \\
\text { RMT; } 10 \text { trains of } 1.2 \mathrm{~s} \\
\text { each, } 10 \text {-s inter-train } \\
\text { interval; total }=120 \\
\text { pulses over } \sim 2 \mathrm{~min}\end{array}$ & $\begin{array}{l}\text { VAS; baseline, } 30 \mathrm{~s} \text { after, } \\
\text { then } 15 / 45 / 90 \text { min after } \\
\text { the stimulation }\end{array}$ & $\begin{array}{l}\text { Pain reduction at } 30 \mathrm{~s} \\
\text { with lowest VAS } \\
\text { score at } 15 \mathrm{~min}\end{array}$ \\
\hline Richlin et al. (129) & Case report & RSD $\operatorname{Exp}=1$ & TENS & na & $\begin{array}{l}30 \text { Sessions ( } 3 \\
\text { sessions/day, } 10 \text { days) }\end{array}$ & $\begin{array}{l}\text { Proximal electrode over } \\
\text { the right femoral } \\
\text { triangle, distal electrode } \\
\text { over the dorsum of the } \\
\text { right foot }\end{array}$ & $\begin{array}{l}40-\mathrm{Hz} \text { TENS at intensity } \\
\text { below discomfort } \\
\text { threshold, } 80-\mu \mathrm{s} \text { pulse } \\
\text { width, } 30 \mathrm{~min}\end{array}$ & $\begin{array}{l}\text { Pain, ROM, } \\
\text { thermography, skin } \\
\text { temperature; at baseline, } \\
5 \text { days after the } \\
\text { beginning of treatment, } 2 \\
\text { days later, and } 4 \text { weeks } \\
\text { from the beginning }\end{array}$ & $\begin{array}{l}\text { Reduction of } \\
\text { hyperalgesia, } \\
\text { increased ROM, } \\
\text { complete pain relief } \\
\text { after the treatment }\end{array}$ \\
\hline $\begin{array}{l}\text { Robaina et al. } \\
\text { (130) }\end{array}$ & Cohort study & RSD Exp $=26$ & TENS & na & $\begin{array}{l}\text { Various depending on } \\
\text { the patient (2-5 } \\
\text { sessions/day, multiple } \\
\text { days) }\end{array}$ & $\begin{array}{l}\text { Painful area or proximal } \\
\text { area next to painful area } \\
\text { or nerve trunk }\end{array}$ & $\begin{array}{l}80-120-\mathrm{Hz} \text { TENS at } \\
\text { intensity at parasthesia } \\
\text { threshold (50-200 } \mu \mathrm{s} \\
\text { pulse width), } 30 \text { to } \\
60 \text { min depending on } \\
\text { the patient }\end{array}$ & $\begin{array}{l}\text { VAS, MPQ; at baseline } \\
\text { and follow-up over } \\
\text { 10-36 months }\end{array}$ & $\begin{array}{l}N=20 / 29 \text { with } \\
\text { good/excellent pain } \\
\text { reduction }\end{array}$ \\
\hline Schmid et al. (131) & Case report & $\begin{array}{l}\text { CRPS type not specified } \\
\operatorname{Exp}=1\end{array}$ & $\begin{array}{l}\text { Anodal tDCS }+ \\
\text { sensorimotor hand } \\
\text { training }\end{array}$ & Sham stimulation & 1 Session & Contralateral M1 & $\begin{array}{l}\text { Anodal tDCS for } 20 \mathrm{~min} \text {. } \\
\text { No other information } \\
\text { provided }\end{array}$ & $\begin{array}{l}\text { Specific sensorimotor } \\
\text { hand training, VAS; pre- } \\
\text { and post-tDCS testing }\end{array}$ & $\begin{array}{l}\text { Pain reduction and } \\
\text { improved } \\
\text { performance on ST }\end{array}$ \\
\hline Stilz et al. (132) & Case report & RSD $\operatorname{Exp}=1$ & TENS & na & $\begin{array}{l}2 \text { Weeks, number of } \\
\text { sessions not reported }\end{array}$ & $\begin{array}{l}\text { Proximal electrode over } \\
\text { the right femoral } \\
\text { triangle, distal electrode } \\
\text { over the right foot } \\
\text { dorsum }\end{array}$ & $\begin{array}{l}50-\mathrm{Hz} \text { TENS at } 3.5 \mathrm{~mA} \text {, } \\
\text { no other information } \\
\text { provided }\end{array}$ & $\begin{array}{l}\text { Clinical evaluation of pain } \\
\text { and physical outcomes }\end{array}$ & $\begin{array}{l}\text { Reduction of pain, } \\
\text { hyperesthesia, edema } \\
\text { and cyanosis. Pain } \\
\text { was still absent after } \\
1 \text { month }\end{array}$ \\
\hline
\end{tabular}

Acronyms of population. RSD, Reflex Sympathetic Dystrophy; SA, Sudeck's Atrophy; CRPS, Complex Regional Pain Syndrome.

Acronyms of intervention. TENS, transcutaneous electric current stimulation; tDCS, transcutaneous direct current stimulation; rTMS, repetitive transcranial magnetic stimulation; iTBS, intermittent theta burst stimulation.

Acronyms of scales and outcomes. ROM, range of motion; VAS, visual analog scale; MPQ, McGill Pain Questionnaire; SF-36, 36-Item Short Form Survey; HDRS, Hamilton Rating Scale for Depression; ST, sensorimotor hand training;

Clinical evaluation: therapist judgment without scales; na, not available. 
the pain, VAS scores were reported immediately after the end of the stimulation and 2 weeks after. Of note, the magnitude of pain reduction was similar between patients having undergone a single session $(n=6)$ and those having been enrolled in five sessions one time a day $(n=15)$.

\section{rPMS}

One study used rPMS in CRPS (67). Ten series of $10 \mathrm{~s}$ of $20 \mathrm{~Hz}$ rPMS at $120 \%$ of spinal RMT were applied over the cervical nerve roots innervating muscles of the painful area. The authors reported that the amplitudes of MEP to TMS of M1 were smaller on both sides in CRPS than in pain-free participants. The after-effects of rPMS in this study were limited to the lengthening, in pain-free participants only, of the duration of the contralateral and ipsilateral cortical silent periods, which informs on the level of M1 and interhemispheric inhibition, respectively. Unfortunately, this study did not collect any clinical outcomes.

\section{tDCS}

Three studies investigated the after-effects of anodal tDCS applied over M1 contralateral to the CRPS hand, two case studies (131), and one randomized parallel single-blind study (125). Of note, these studies used tDCS as an add-on of sensorimotor training (131), TENS over the painful area (123), and graded motor imagery (125). Schmid et al. reported that anodal tDCS + sensorimotor training reduced pain intensity and improved the pattern identification during ST, as compared to sham tDCS + sensorimotor training (131). The second study (123) reported that anodal tDCS + TENS one time a day a day for 5 consecutive days slightly reduced pain intensity and unpleasantness, as compared to tDCS alone. Lagueux et al. tested tDCS + graded motor imagery in 11 people with CRPS type I (125). Precisely, the participants underwent 6 weeks of graded motor imagery, and anodal tDCS of M1 was added one time a day for 5 days in a row in the first 2 weeks of graded motor imagery, then, one time a week for the remaining 4 weeks of graded motor imagery. The authors reported that this did not reduce pain more than in the control group of 11 other patients having undergone sham tDCS + graded motor imagery with the same parameters (125). Of note, it has never been reported either that protocols of tDCS alone could improve pain management in CRPS (112).

\section{TENS}

TENS after-effects in CRPS pain management have been described in numerous interesting case reports and case series since the late 1970s, both in children and adults. However, robust data-evidence-based studies are missing and the efficacy of TENS has not yet been established. Current evidence is limited by the case report designs, the large variety of protocols employed or the missing details in the protocol, the heterogeneous cohorts of patients, and the lack of appropriate control conditions in most cases. However, given the high acceptance and safety of this device, it is almost always worthwhile to consider TENS as part of a multidisciplinary approach (133). For example, three case studies in children aged 10, 6, and 3.5 years old, respectively (126), and one case report in a 43-year-old woman (121) reported that TENS applied over acupuncture points or painful areas, at low or high frequencies and for one or several sessions, decreased pain, hyperesthesia, hyperalgesia, edema, cyanosis if any, and, in parallel, improved the range of motion (ROM) at the painful joint. Two other series of cases used various stimulation protocols between children and with limited details provided in the articles: TENS coupled with home-based physical therapy reduced pain symptoms in $9 / 10$ cases with complete remission within 2 months in $7 / 10$ cases (124) and TENS alone reduced pain in 20/29 cases (130). More recently, a randomized clinical trial tested $100 \mathrm{~Hz}$ TENS as an add-on to a standard physical therapy program (contrast bath, whirlpool bath, and physical exercise) in 15 people with type-1 CRPS. The authors showed that 15 sessions of TENS + standard physical therapy program reduced pain scores and edema and increased the second-tothird fingers ROM more than in a group of 15 other patients who underwent sham TENS + standard physical therapy program. It was concluded that the addition of TENS to standard physical therapy programs significantly contributed to clinical recovery in CRPS (120).

\section{Research and Clinical Prospective}

Non-invasive neurostimulation techniques have already been reported to influence neurophysiological markers in various chronic pain conditions, such as fibromyalgia (134, 135), neuropathic pain (136-140), lower back pain (107, 141-143), deafferentation pain (144), or phantom limb pain (145). Evidence is slowly piling up and the work from Moisset et al. (109) in chronic pain reviewed the analgesic effects of rTMS of M1 or of dorsolateral PFC and related this pain reduction to the changes of corticospinal excitability that can last for weeks. In a recent systematic review (146), the use of high-frequency rTMS over M1 was acknowledged level A of evidence in neuropathic pain, level B in CRPS, and the use of high-frequency rTMS over the left dorsolateral PFC was acknowledged level B of evidence in the control of pain. It is thus surprising that, despite promising data in other chronic pain conditions, only a few randomized clinical studies tested these techniques in CRPS (112). A possible explanation is that CRPS is a rare syndrome characterized by a large variabilty of clinical profiles, thus making it difficult to run larger studies with randomized placebo-controlled designs. In fact, two systematic reviews rated with very low quality of evidence on the therapeutic effects of non-invasive neurostimulation in CRPS on pain intensity, but this may be due to small sample size and short follow-up $(99,147)$.

Future research is warranted to better determine whether non-invasive neurostimulation, alone or combined with other treatments, is efficient to reduce CRPS severity. To this end, studies ought to clearly identify if there are responders and nonresponders to one or another technique if some data or variables collected at baseline can be predictors of responsiveness, and if all brain changes detected are specific to CRPS, or commonly related to chronic pain, or, for example, a consequence of the limb non-use, i.e., not directly related to pain. Due to the high variability of CRPS profiles, it is expected that not all 
people will respond to non-invasive neurostimulation to the same extent. It will thus be crucial to customize an individual approach owing to brain changes and the integrity of the corticospinal system.

\section{CONCLUSION}

Knowledge of CRPS neurophysiopathology has evolved rapidly in the last decades, with more evidence of neural changes involvement in the chronicization, the symptoms and the resistance to conventional treatment. However, literature on non-invasive neurostimulation trials to influence these neural changes remains scarce. This is despite evidence from other pain conditions of sustained pain decrease and function improvement in parallel with a resolution of maladaptive neural plasticity. The current review lays the stress on the fact that non-invasive neurostimulation of the brain or of nerve/muscles/spinal roots, alone or in combination with other treatments, represents a fertile ground for further investigations on more efficient interventions in CRPS management.

\section{REFERENCES}

1. Borchers AT, Gershwin ME. Complex regional pain syndrome: a comprehensive and critical review. Autoimmun Rev. (2014) 13:242-65. doi: 10.1016/j.autrev.2013.10.006

2. Harden RN, Bruehl S, Perez RS, Birklein F, Marinus J, Maihofner C, et al. Validation of proposed diagnostic criteria (the "budapest criteria”) for complex regional pain syndrome. Pain. (2010) 150:26874. doi: 10.1016/j.pain.2010.04.030

3. Merskey HE. Classification of chronic pain: descriptions of chronic pain syndromés and definitions of pain terms. Pain. (1986) 3:S1-226.

4. Merskey H, Bogduk N. Classification of Chronic Pain, IASP Task Force on Taxonomy. Seattle, WA: International Association for the Study of Pain Press. (1994). Available online at: www. iasp-painorg

5. Harden RN, Oaklander AL, Burton AW, Perez RS, Richardson K, Swan M, et al. Complex regional pain syndrome: practical diagnostic and treatment guidelines. Pain Med. (2013) 14:180-229. doi: 10.1111/pme.12033

6. Veldman PH, Reynen HM, Arntz IE, Goris RJA. Signs and symptoms of reflex sympathetic dystrophy: prospective study of 829 patients. Lancet. (1993) 342:1012-6. doi: 10.1016/0140-6736(93)92877-V

7. Abu-Arafeh H, Abu-Arafeh I. Complex regional pain syndrome in children: incidence and clinical characteristics. Arch Dis Childh. (2016) 101:71923. doi: 10.1136/archdischild-2015-310233

8. Sandroni P, Benrud-Larson LM, McClelland RL, Low PA. Complex regional pain syndrome type I: incidence and prevalence in olmsted county, a population-based study. Pain. (2003) 103:199-207. doi: 10.1016/S0304-3959(03)00065-4

9. de Mos M, Huygen FJ, Dieleman JP, Koopman JS, Stricker BH, Sturkenboom MC. Medical history and the onset of complex regional pain syndrome (CRPS). Pain. (2008) 139:458-66. doi: 10.1016/j.pain.2008.07.002

10. Bruehl S. Complex regional pain syndrome. BMJ. (2015) 351:h2730. doi: 10.1136/bmj.h2730

11. van Velzen GA, Perez RS, van Gestel MA, Huygen FJ, van Kleef M, van Eijs F, et al. Health-related quality of life in 975 patients with complex regional pain syndrome type 1. Pain. (2014) 155:629-34. doi: 10.1016/j.pain.2013.12.017

12. Geertzen JH, Dijkstra PU, Sonderen Lv E, Groothoff JW, Duis Jt H, Eisma WH. Relationship between impairments, disability and handicap in reflex sympathetic dystrophy patients: a long-term follow-up study. Clin Rehabil. (1998) 12:402-12. doi: 10.1191/026921598676761735

13. Bean DJ, Johnson MH, Kydd RR. Relationships between psychological factors, pain, and disability in complex regional pain syndrome and low back pain. Clin J Pain. (2014) 30:647-53. doi: 10.1097/AJP.0000000000000007

\section{AUTHOR CONTRIBUTIONS}

FAD, AZ, and CS wrote the manuscript. AZ and CS edited the manuscript. All authors listed have made a substantial, direct and intellectual contribution to the work, and approved it for publication.

\section{FUNDING}

The work was supported by the Chronic Pain Network funded by the strategy for patient-oriented research (SPOR) of the Canadian Institutes of Health Research (CS's lab). AZ was supported by a doctorate studentship from the Center Thématique de Recherche en Neurosciences (CTRN-Université Laval, Québec). FAD was supported by a master's studentship for health professionals from the Fonds de Recherche du Québec-Santé (FRQS).

\section{ACKNOWLEDGMENTS}

The authors acknowledge Estelle Gouriou, Ph.D. candidate, for the conception and revision of Figure 1.

14. de Mos M, de Bruijn AG, Huygen FJ, Dieleman JP, Stricker BH, Sturkenboom MC. The incidence of complex regional pain syndrome: a population-based study. Pain. (2007) 129:12-20. doi: 10.1016/j.pain.2006.09.008

15. Rodham K, Gavin J, Coulson N, Watts L. Co-creation of information leaflets to meet the support needs of people living with complex regional pain syndrome (CRPS) through innovative use of wiki technology. Inform Health Soc Care. (2016) 41:325-39. doi: 10.3109/17538157.2015.1008491

16. Bruehl S, Warner DS. An update on the pathophysiology of complex regional pain syndrome. J Am Soc Anesthesiol. (2010) 113:713-25. doi: 10.1097/ALN.0b013e3181e3db38

17. Marinus J, Moseley GL, Birklein F, Baron R, Maihöfner C, Kingery WS, et al. Clinical features and pathophysiology of complex regional pain syndrome. Lancet Neurol. (2011) 10:637-48. doi: 10.1016/S1474-4422(11)70106-5

18. Maihofner C, Handwerker HO, Neundorfer B, Birklein F. Patterns of cortical reorganization in complex regional pain syndrome. Neurology. (2003) 61:1707-15. doi: 10.1212/01.WNL.0000098939.02752.8E

19. Maihofner C, Seifert F, Markovic K. Complex regional pain syndromes: new pathophysiological concepts and therapies. Eur J Neurol. (2010) 17:64960. doi: 10.1111/j.1468-1331.2010.02947.x

20. Janig W, Baron R. Complex regional pain syndrome is a disease of the central nervous system. Clin Auton Res. (2002) 12:150-64. doi: 10.1007/s10286-002-0022-1

21. Birklein F, Schmelz M. Neuropeptides, neurogenic inflammation and complex regional pain syndrome (CRPS). Neurosci Lett. (2008) 437:199202. doi: 10.1016/j.neulet.2008.03.081

22. Birklein F, Schmelz M, Schifter S, Weber M. The important role of neuropeptides in complex regional pain syndrome. Neurology. (2001) 57:2179-84. doi: 10.1212/WNL.57.12.2179

23. Eisenberg E, Chistyakov AV, Yudashkin M, Kaplan B, Hafner H, Feinsod M. Evidence for cortical hyperexcitability of the affected limb representation area in CRPS: a psychophysical and transcranial magnetic stimulation study. Pain. (2005) 113:99-105. doi: 10.1016/j.pain.2004.09.030

24. Parkitny L, McAuley JH, Di Pietro F, Stanton TR, O'Connell $\mathrm{NE}$, Marinus J, et al. Inflammation in complex regional pain syndrome: a systematic review and meta-analysis. Neurology. (2013) 80:106-17. doi: 10.1212/WNL.0b013e31827blaal

25. Baron R, Hans G, Dickenson AH. Peripheral input and its importance for central sensitization. Annals of neurology. (2013) 74:630-6. doi: 10.1002/ana.24017

26. Wei T, Guo TZ, Li WW, Kingery WS, Clark JD. Acute versus chronic phase mechanisms in a rat model of CRPS. J Neuroinflammation. (2016) 13:14. doi: 10.1186/s12974-015-0472-8 
27. Gallagher JJ, Tajerian M, Guo T, Shi X, Li W, Zheng M, et al. Acute and chronic phases of complex regional pain syndrome in mice are accompanied by distinct transcriptional changes in the spinal cord. Mol Pain. (2013) 9:43. doi: 10.1186/1744-8069-9-40

28. Oaklander AL, Rissmiller JG, Gelman LB, Zheng L, Chang Y, Gott R. Evidence of focal small-fiber axonal degeneration in complex regional pain syndrome-I (reflex sympathetic dystrophy). Pain. (2006) 120:23543. doi: 10.1016/j.pain.2005.09.036

29. Albrecht PJ, Hines S, Eisenberg E, Pud D, Finlay DR, Connolly MK, et al. Pathologic alterations of cutaneous innervation and vasculature in affected limbs from patients with complex regional pain syndrome. Pain. (2006) 120:244-66. doi: 10.1016/j.pain.2005.10.035

30. Schlereth T, Drummond PD, Birklein F. Inflammation in CRPS: role of the sympathetic supply. Auton Neurosci. (2014) 182:102-7. doi: 10.1016/j.autneu.2013.12.011

31. Wasner G, Heckmann K, Maier C, Baron R. Vascular abnormalities in acute reflex sympathetic dystrophy (CRPS I): complete inhibition of sympathetic nerve activity with recovery. Arch Neurol. (1999) 56:61320. doi: 10.1001/archneur.56.5.613

32. Gradl G, Schürmann M. Sympathetic dysfunction as a temporary phenomenon in acute posttraumatic CRPS I. Clin Auton Res. (2005) 15:2934. doi: $10.1007 / \mathrm{s} 10286-005-0237-\mathrm{z}$

33. Casale R, Elam M. Normal sympathetic nerve activity in a reflex sympathetic dystrophy with marked skin vasoconstriction. J Auton Nerv Syst. (1992) 41:215-9. doi: 10.1016/0165-1838(92)90061-K

34. Drummond PD, Finch PM, Gibbins I. Innervation of hyperalgesic skin in patients with complex regional pain syndrome. Clin J Pain. (1996) 12:22231. doi: 10.1097/00002508-199609000-00010

35. Goldstein DS, Tack C, Li ST. Sympathetic innervation and function in reflex sympathetic dystrophy. Ann Neurol. (2000) 48:4959. doi: 10.1002/1531-8249(200007)48:1<49::AID-ANA8>3.0.CO;2-T

36. Knudsen LF, Terkelsen AJ, Drummond PD, Birklein F. Complex regional pain syndrome: a focus on the autonomic nervous system. Clin Auton Res. (2019) 29:457-67. doi: 10.1007/s10286-019-00612-0

37. Kohr D, Singh P, Tschernatsch M, Kaps M, Pouokam E, Diener M, et al. Autoimmunity against the $\beta 2$ adrenergic receptor and muscarinic2 receptor in complex regional pain syndrome. Pain. (2011) 152:2690700. doi: $10.1016 /$ j.pain.2011.06.012

38. Dubuis E, Thompson V, Leite MI, Blaes F, Maihöfner C, Greensmith D, et al. Longstanding complex regional pain syndrome is associated with activating autoantibodies against alpha-1a adrenoceptors. Pain. (2014) 155:240817. doi: 10.1016/j.pain.2014.09.022

39. Birklein F, Dimova V. Complex regional pain syndrome-up-to-date. Pain Rep. (2017) 2:e624. doi: 10.1097/PR9.0000000000000624

40. Geha PY, Baliki MN, Harden RN, Bauer WR, Parrish TB, Apkarian AV. The brain in chronic CRPS pain: abnormal gray-white matter interactions in emotional and autonomic regions. Neuron. (2008) 60:57081. doi: 10.1016/j.neuron.2008.08.022

41. Shokouhi M, Clarke C, Morley-Forster P, Moulin DE, Davis KD, St Lawrence K. Structural and functional brain changes at early and late stages of complex regional pain syndrome. J Pain. (2018) 19:14657. doi: 10.1016/j.jpain.2017.09.007

42. Barad MJ, Ueno T, Younger J, Chatterjee N, Mackey S. Complex regional pain syndrome is associated with structural abnormalities in pain-related regions of the human brain. J Pain. (2014) 15:197203. doi: 10.1016/j.jpain.2013.10.011

43. Azqueta-Gavaldon M, Youssef AM, Storz C, Lemme J, Schulte-Göcking $\mathrm{H}$, Becerra L, et al. Implications of the putamen in pain and motor deficits in complex regional pain syndrome. Pain. (2020) 161:595608. doi: 10.1097/j.pain.0000000000001745

44. Zhou G, Hotta J, Lehtinen MK, Forss N, Hari R. Enlargement of choroid plexus in complex regional pain syndrome. Sci Rep. (2015) 5:14329. doi: $10.1038 /$ srep 14329

45. Mancini F, Wang AP, Schira MM, Isherwood ZJ, McAuley JH, Iannetti GD, et al. Fine-Grained mapping of cortical somatotopies in chronic complex regional pain syndrome. J Neurosci. (2019) 39:9185-96. doi: 10.1523/JNEUROSCI.2005-18.2019
46. Pleger B, Tegenthoff M, Schwenkreis P, Janssen F, Ragert P, Dinse $\mathrm{HR}$, et al. Mean sustained pain levels are linked to hemispherical side-to-side differences of primary somatosensory cortex in the complex regional pain syndrome I. Exp Brain Res. (2004) 155:115-9. doi: 10.1007/s00221-003-1738-4

47. Di Pietro F, McAuley JH, Parkitny L, Lotze M, Wand BM, Moseley GL, et al. Primary somatosensory cortex function in complex regional pain syndrome: a systematic review and meta-analysis. J Pain. (2013) 14:100118. doi: 10.1016/j.jpain.2013.04.001

48. Vartiainen NV, Kirveskari E, Forss N. Central processing of tactile and nociceptive stimuli in complex regional pain syndrome. Clin Neurophysiol. (2008) 119:2380-8. doi: 10.1016/j.clinph.2008.06.008

49. Juottonen K, Gockel M, Silen T, Hurri H, Hari R, Forss N. Altered central sensorimotor processing in patients with complex regional pain syndrome. Pain. (2002) 98:315-23. doi: 10.1016/S0304-3959(02)00119-7

50. Pfannmoller J, Strauss S, Langner I, Usichenko T, Lotze M. Investigations on maladaptive plasticity in the sensorimotor cortex of unilateral upper limb CRPS I patients. Restor Neurol Neurosci. (2019) 37:14353. doi: $10.3233 / \mathrm{RNN}-180886$

51. Krause P, Forderreuther S, Straube A. TMS motor cortical brain mapping in patients with complex regional pain syndrome type I. Clin Neurophysiol. (2006) 117:169-76. doi: 10.1016/j.clinph.2005.09.012

52. Bolwerk A, Seifert F, Maihofner C. Altered resting-state functional connectivity in complex regional pain syndrome. J Pain. (2013) 14:110715.e8. doi: 10.1016/j.jpain.2013.04.007

53. Zang Y-F, Baliki MN, Mansour AR, Baria AT, Apkarian AV. Functional reorganization of the default mode network across chronic pain conditions. PLoS ONE. (2014) 9:e106133. doi: 10.1371/journal.pone.0106133

54. Kucyi A, Moayedi M, Weissman-Fogel I, Goldberg MB, Freeman BV, Tenenbaum HC, et al. Enhanced medial prefrontaldefault mode network functional connectivity in chronic pain and its association with pain rumination. $J$ Neurosci. (2014) 34:3969-75. doi: 10.1523/JNEUROSCI.5055-13.2014

55. Shiraishi S, Kobayashi H, Nihashi T, Kato K, Iwano S, Nishino M, et al. Cerebral glucose metabolism change in patients with complex regional pain syndrome: a PET study. Radiat Med. (2006) 24:33544. doi: 10.1007/s11604-006-0035-0

56. Fukumoto M, Ushida T, Zinchuk VS, Yamamoto H, Yoshida S. Contralateral thalamic perfusion in patients with reflex sympathetic dystrophy syndrome. Lancet. (1999) 354:1790-1. doi: 10.1016/S0140-6736(99)03746-0

57. Fukui S. Evaluation of thalamic neural activity in CRPS type 1 patients by proton MR spectroscopy: a correlative study with rCBF. J Anesth. (2003) 17:142-4. doi: 10.1007/s005400300033

58. Freund W, Wunderlich AP, Stuber G, Mayer F, Steffen P, Mentzel $M$, et al. Different activation of opercular and posterior cingulate cortex (PCC) in patients with complex regional pain syndrome (CRPS I) compared with healthy controls during perception of electrically induced pain: a functional MRI study. Clin J Pain. (2010) 26:33947. doi: 10.1097/AJP.0b013e3181cb4055

59. Puchalski P, Zyluk A. Results of the treatment of chronic, refractory crps with ketamine infusions: a preliminary report. Handchir Mikrochir Plast Chir. (2016) 48:143-7. doi: 10.1055/s-0042-108650

60. Maihofner C, Baron R, DeCol R, Binder A, Birklein F, Deuschl G, et al. The motor system shows adaptive changes in complex regional pain syndrome. Brain. (2007) 130:2671-87. doi: 10.1093/brain/awm131

61. Lenz M, Hoffken O, Stude P, Lissek S, Schwenkreis P, Reinersmann A, et al. Bilateral somatosensory cortex disinhibition in complex regional pain syndrome type I. Neurology. (2011) 77:1096101. doi: 10.1212/WNL.0b013e31822e1436

62. Galea V. Bilateral somatosensory cortex disinhibition in complex regional pain syndrome type I. Yearb Sports Med. (2012) 2012:308-310. doi: 10.1016/j.yspm.2012.01.001

63. Kirveskari E, Vartiainen NV, Gockel M, Forss N. Motor cortex dysfunction in complex regional pain syndrome. Clin Neurophysiol. (2010) 121:108591. doi: 10.1016/j.clinph.2010.01.032

64. Schwenkreis P, Janssen F, Rommel O, Pleger B, Volker B, Hosbach $\mathrm{I}$, et al. Bilateral motor cortex disinhibition in complex regional pain 
syndrome (CRPS) type I of the hand. Neurology. (2003) 61:5159. doi: 10.1212/WNL.61.4.515

65. Morgante F, Naro A, Terranova C, Russo M, Rizzo V, Risitano G, et al. Normal sensorimotor plasticity in complex regional pain syndrome with fixed posture of the hand. Mov Disord. (2017) 32:14957. doi: $10.1002 / \mathrm{mds} .26836$

66. Turton AJ, McCabe CS, Harris N, Filipovic SR. Sensorimotor integration in complex regional pain syndrome: a transcranial magnetic stimulation study. Pain. (2007) 127:270-5. doi: 10.1016/j.pain.2006.08.021

67. Krause P, Foerderreuther S, Straube A. Effects of conditioning peripheral repetitive magnetic stimulation in patients with complex regional pain syndrome. Neurol Res. (2005) 27:412-7. doi: 10.1179/016164105X17224

68. Krause P, Foerderreuther S, Straube A. Bilateral motor cortex disinhibition in complex regional pain syndrome (CRPS) type I of the hand. Neurology. (2004) 62:1654; author reply 1654-5. doi: 10.1212/WNL.62.9.1654

69. van Velzen GA, Marinus J, van Dijk JG, van Zwet EW, Schipper IB, van Hilten JJ. Motor cortical activity during motor tasks is normal in patients with complex regional pain syndrome. J Pain. (2015) 16:8794. doi: 10.1016/j.jpain.2014.10.010

70. Lüscher C, Malenka RC. NMDA receptor-dependent long-term potentiation and long-term depression (LTP/LTD). Cold Spring Harbor Perspect Biol. (2012) 4:a005710. doi: 10.1101/cshperspect.a005710

71. Hasselmo ME. Neuromodulation and cortical function: modeling the physiological basis of behavior. Behav Brain Res. (1995) 67:1-27. doi: 10.1016/0166-4328(94)00113-T

72. Massé-Alarie H, Schneider C. Cerebral reorganization in chronic low back pain and neurostimulation to improve motor control. Neurophysiol Clin. (2011) 41:51-60. doi: 10.1016/j.neucli.2011.03.004

73. Pell GS, Roth Y, Zangen A. Modulation of cortical excitability induced by repetitive transcranial magnetic stimulation: influence of timing and geometrical parameters and underlying mechanisms. Prog Neurobiol. (2011) 93:59-98. doi: 10.1016/j.pneurobio.2010.10.003

74. Woolf CJ. Central sensitization: implications for the diagnosis and treatment of pain. Pain. (2011) 152:S2-15. doi: 10.1016/j.pain.2010.09.030

75. Azari P, Lindsay DR, Briones D, Clarke C, Buchheit T, Pyati S. Efficacy and safety of ketamine in patients with complex regional pain syndrome. CNS Drugs. (2012) 26:215-28. doi: 10.2165/11595200-000000000-00000

76. Ushida T, Tani T, Kanbara T, Zinchuk VS, Kawasaki M, Yamamoto H. Analgesic effects of ketamine ointment in patients with complex regional pain syndrome type 1. Reg Anesth Pain Med. (2002) 27:5248. doi: 10.1053/rapm.2002.35517

77. Correll GE, Maleki J, Gracely EJ, Muir JJ, Harbut RE. Subanesthetic ketamine infusion therapy: a retrospective analysis of a novel therapeutic approach to complex regional pain syndrome. Pain Med. (2004) 5:26375. doi: 10.1111/j.1526-4637.2004.04043.x

78. Gustin SM, Schwarz A, Birbaumer N, Sines N, Schmidt AC, Veit R, et al. NMDA-receptor antagonist and morphine decrease CRPS-pain and cerebral pain representation. Pain. (2010) 151:69-76. doi: 10.1016/j.pain.2010.06.022

79. Pleger B, Tegenthoff M, Ragert P, Forster AF, Dinse HR, Schwenkreis $\mathrm{P}$, et al. Sensorimotor retuning [corrected] in complex regional pain syndrome parallels pain reduction. Ann Neurol. (2005) 57:425-9. doi: 10.1002/ana.20394

80. Pleger B, Ragert P, Schwenkreis P, Forster AF, Wilimzig C, Dinse H, et al. Patterns of cortical reorganization parallel impaired tactile discrimination and pain intensity in complex regional pain syndrome. Neuroimage. (2006) 32:503-10. doi: 10.1016/j.neuroimage.2006.03.045

81. Azqueta-Gavaldon M, Schulte-Gocking H, Storz C, Azad S, Reiners A, Borsook D, et al. Basal ganglia dysfunction in complex regional pain syndrome - a valid hypothesis? Eur J Pain. (2017) 21:41524. doi: $10.1002 /$ ejp. 975

82. Linnman C, Becerra L, Lebel A, Berde C, Grant PE, Borsook D. Transient and persistent pain induced connectivity alterations in pediatric complex regional pain syndrome. PLOS ONE. (2013) 8:e57205. doi: 10.1371/journal.pone.0057205

83. Lebel A, Becerra L, Wallin D, Moulton EA, Morris S, Pendse G, et al. fMRI reveals distinct CNS processing during symptomatic and recovered complex regional pain syndrome in children. Brain. (2008) 131:185479. doi: $10.1093 /$ brain/awn123
84. Nardone R, Brigo F, Holler Y, Sebastianelli L, Versace V, Saltuari L, et al. Transcranial magnetic stimulation studies in complex regional pain syndrome type I: a review. Acta Neurol Scand. (2018) 137:15864. doi: 10.1111/ane.12852

85. Di Lazzaro V, Rothwell J, Capogna M. Noninvasive stimulation of the human brain: activation of multiple cortical circuits. Neuroscientist. (2017) 24:246-60. doi: 10.1177/1073858417717660

86. Lefaucheur JP, Drouot X, Menard-Lefaucheur I, Keravel Y, Nguyen JP. Motor cortex rTMS restores defective intracortical inhibition in chronic neuropathic pain. Neurology. (2006) 67:1568-74. doi: 10.1212/01.wnl.0000242731.10074.3c

87. Costigan M, Scholz J, Woolf CJ. Neuropathic pain: a maladaptive response of the nervous system to damage. Ann Rev Neurosci. (2009) 32:132. doi: $10.1146 /$ annurev.neuro. 051508.135531

88. Maihofner C, Handwerker HO, Neundorfer B, Birklein F. Cortical reorganization during recovery from complex regional pain syndrome. Neurology. (2004) 63:693-701. doi: 10.1212/01.WNL.0000134661.46658.B0

89. Sorel M, Zrek N, Locko B, Armessen C, Ayache SS, Lefaucheur J-P. A reappraisal of the mechanisms of action of ketamine to treat complex regional pain syndrome in the light of cortical excitability changes. Clin Neurophysiol. (2018) 129:990-1000. doi: 10.1016/j.clinph.2018.02.124

90. Truchon R, MarquetteM. Algorithme de Prise en Charge Interdisciplinaire du Syndrome de Douleur Régionale Complexe (SDRC). Quebec City, QC: Ministère de la Santé et des Services Sociaux (2015).

91. Stanton TR, Wand BM, Carr DB, Birklein F, Wasner GL, O'Connell NE. Local anaesthetic sympathetic blockade for complex regional pain syndrome. Cochrane Database Syst Rev. (2013) CD004598. doi: 10.1002/14651858.CD004598.pub3

92. Cepeda MS, Carr DB, Lau J. Local anaesthetic sympathetic blockade for complex regional pain syndrome. Cochrane Database Syst Rev. (2005) CD004598. doi: 10.1002/14651858.CD004598.pub2

93. O'Connell NE, Wand BM, Gibson W, Carr DB, Birklein F, Stanton TR. Local anaesthetic sympathetic blockade for complex regional pain syndrome. Cochrane Database Syst Rev. (2016) 7:CD004598. doi: 10.1002/14651858.CD004598.pub4

94. Connolly SB, Prager JP, Harden RN. A systematic review of ketamine for complex regional pain syndrome. Pain Med. (2015) 16:943-69. doi: 10.1111/pme.12675

95. Tajerian M, Leu D, Yang P, Huang TT, Kingery WS, Clark JD. Differential efficacy of ketamine in the acute versus chronic stages of complex regional pain syndrome in mice. Anesthesiology. (2015) 123:143547. doi: 10.1097/ALN.0000000000000889

96. Oerlemans HM, Oostendorp RA, de Boo T, Goris RJA. Pain and reduced mobility in complex regional pain syndrome I: outcome of a prospective randomised controlled clinical trial of adjuvant physical therapy versus occupational therapy. Pain. (1999) 83:77-83. doi: 10.1016/S0304-3959(99)00080-9

97. Oerlemans HM, Oostendorp RA, de Boo T, van der Laan L, Severens JL, Goris RJA. Adjuvant physical therapy versus occupational therapy in patients with reflex sympathetic dystrophy/complex regional pain syndrome type I. Arch Phys Med Rehabi. (2000) 81:49-56. doi: 10.1016/S0003-9993(00)90221-1

98. Goh EL, Chidambaram S, Ma D. Complex regional pain syndrome: a recent update. Burns Trauma. (2017) 5:2. doi: 10.1186/s41038-016-0066-4

99. O'Connell NE, Wand BM, McAuley J, Marston L, Moseley GL. Interventions for treating pain and disability in adults with complex regional pain syndrome. Cochrane Database Syst Rev. (2013) 2013:CD009416. doi: 10.1002/14651858.CD009416.pub2

100. de Jong JR, Vlaeyen JW, de Gelder JM, Patijn J. Pain-related fear, perceived harmfulness of activities, and functional limitations in complex regional pain syndrome type I. J Pain. (2011) 12:1209-18. doi: 10.1016/j.jpain.2011.06.010

101. Marinus J, Perez RS, van Eijs F, van Gestel MA, Geurts JW, Huygen FJ, et al. the role of pain coping and kinesiophobia in patients with complex regional pain syndrome type 1 of the legs. Clin J Pain. (2013) 29:5639. doi: 10.1097/AJP.0b013e31826f9a8a

102. Moseley GL. Graded motor imagery is effective for long-standing complex regional pain syndrome: a randomised controlled trial. Pain. (2004) 108:1928. doi: 10.1016/j.pain.2004.01.006 
103. Naro A, Milardi D, Russo M, Terranova C, Rizzo V, Cacciola A, et al. Non-invasive brain stimulation, a tool to revert maladaptive plasticity in neuropathic pain. Front Hum Neurosci. (2016) 10:376. doi: 10.3389/fnhum.2016.00376

104. Bolognini N, Pascual-Leone A, Fregni F. Using non-invasive brain stimulation to augment motor training-induced plasticity. J Neuroeng Rehabil. (2009) 6:8. doi: 10.1186/1743-0003-6-8

105. Engineer ND, Riley JR, Seale JD, Vrana WA, Shetake JA, Sudanagunta SP, et al. Reversing pathological neural activity using targeted plasticity. Nature. (2011) 470:101-104. doi: 10.1038/nature09656

106. Masse-Alarie H, Schneider C. Revisiting the corticomotor plasticity in low back pain: challenges and perspectives. Healthcare. (2016) 4:67. doi: 10.3390/healthcare4030067

107. Masse-Alarie H, Beaulieu LD, Preuss R, Schneider C. Repetitive peripheral magnetic neurostimulation of multifidus muscles combined with motor training influences spine motor control and chronic low back pain. Clin Neurophysiol. (2017) 128:442-53. doi: 10.1016/j.clinph.2016.12.020

108. Beaulieu LD, Schneider C. Repetitive peripheral magnetic stimulation to reduce pain or improve sensorimotor impairments: a literature review on parameters of application and afferents recruitment. Neurophysiol Clin. (2015) 45:223-37. doi: 10.1016/j.neucli.2015.08.002

109. Moisset X, de Andrade DC, Bouhassira D. From pulses to pain relief: an update on the mechanisms of rTMS-induced analgesic effects. Eur J Pain. (2016) 20:689-700. doi: 10.1002/ejp.811

110. Krause P, Straube A. Peripheral repetitive magnetic stimulation induces intracortical inhibition in healthy subjects. Neurol Res. (2008) 30:6904. doi: 10.1179/174313208X297959

111. Plow EB, Pascual-Leone A, Machado A. Brain stimulation in the treatment of chronic neuropathic and non-cancerous pain. J Pain. (2012) 13:41124. doi: 10.1016/j.jpain.2012.02.001

112. O'Connell NE, Marston L, Spencer S, DeSouza LH, Wand BM. Non-invasive brain stimulation techniques for chronic pain. Cochrane Database Syst Rev. (2018) 4:CD008208. doi: 10.1002/14651858.CD008208.pub4

113. Martel M, Harvey M-P, Houde F, Balg F, Goffaux P, Léonard G. Unravelling the effect of experimental pain on the corticomotor system using transcranial magnetic stimulation and electroencephalography. Exp Brain Res. (2017) 235:1223-31. doi: 10.1007/s00221-017-4880-0

114. Cuypers K, Leenus DJ, Van Wijmeersch B, Thijs H, Levin O, Swinnen SP, et al. Anodal tDCS increases corticospinal output and projection strength in multiple sclerosis. Neurosci Lett. (2013) 554:151-5. doi: 10.1016/j.neulet.2013.09.004

115. Sluka KA, Walsh D. Transcutaneous electrical nerve stimulation: basic science mechanisms and clinical effectiveness. J Pain. (2003) 4:10921. doi: 10.1054/jpai.2003.434

116. Peng WW, Tang ZY, Zhang FR, Li H, Kong YZ, Iannetti GD, et al. Neurobiological mechanisms of TENS-induced analgesia. Neuroimage. (2019) 195:396-408. doi: 10.1016/j.neuroimage.2019.03.077

117. Choi JC, Kim J, Kang E, Lee JM, Cha J, Kim YJ, et al. Brain mechanisms of pain relief by transcutaneous electrical nerve stimulation: a functional magnetic resonance imaging study. Euro J Pain. (2016) 20:92105. doi: 10.1002/ejp.696

118. Ottoson D, Lundeberg T. Transcutaneous Electrical Nerve Stimulation. Berlin; Heidelberg: Springer (1988). doi: 10.1007/978-3-642-73624-7_2

119. DeSantana JM, Walsh DM, Vance C, Rakel BA, Sluka KA. Effectiveness of transcutaneous electrical nerve stimulation for treatment of hyperalgesia and pain. Curr Rheumatol Rep. (2008) 10:492. doi: 10.1007/s11926-008-0080-z

120. Bilgili A, Cakir T, Dogan SK, Ercalik T, Filiz MB, Toraman F. The effectiveness of transcutaneous electrical nerve stimulation in the management of patients with complex regional pain syndrome: a randomized, double-blinded, placebo-controlled prospective study. J Back Musculoskelet Rehabil. (2016) 29:661-71. doi: 10.3233/BMR-160667

121. Bodenheim R, Bennett JH. Reversal of a Sudeck's atrophy by the adjunctive use of transcutaneous electrical nerve stimulation. A case report. Phys Ther. (1983) 63:1287-8. doi: 10.1093/ptj/63.8.1287

122. Gaertner M, Kong J-T, Scherrer KH, Foote A, Mackey S, Johnson KA. Advancing transcranial magnetic stimulation methods for complex regional pain syndrome: an open-label study of paired theta burst and high-frequency stimulation. Neuromodulation. (2018) 21:409-16. doi: 10.1111/ner.12760
123. Houde F, Harvey MP, Tremblay Labrecque PF, Lamarche F, Lefebvre A, Leonard G. Combining transcranial direct current stimulation and transcutaneous electrical nerve stimulation to relieve persistent pain in a patient suffering from complex regional pain syndrome: a case report. J Pain Res. (2020) 13:467-73. doi: 10.2147/JPR.S226616

124. Kesler RW, Saulsbury FT, Miller LT, Rowlingson JC. Reflex sympathetic dystrophy in children: treatment with transcutaneous electric nerve stimulation. Pediatrics. (1988) 82:728-32.

125. Lagueux E, Bernier M, Bourgault P, Whittingstall K, Mercier C, Leonard G, et al. The effectiveness of transcranial direct current stimulation as an addon modality to graded motor imagery for treatment of complex regional pain syndrome: a randomized proof of concept study. Clin J Pain. (2018) 34:145-54. doi: 10.1097/AJP.0000000000000522

126. Leo KC. Use of electrical stimulation at acupuncture points for the treatment of reflex sympathetic dystrophy in a child. A case report. Phys Ther. (1983) 63:957-9. doi: 10.1093/ptj/63.6.957

127. Picarelli H, Teixeira MJ, de Andrade DC, Myczkowski ML, Luvisotto TB, Yeng LT, et al. Repetitive transcranial magnetic stimulation is efficacious as an add-on to pharmacological therapy in complex regional pain syndrome (CRPS) type I. J Pain. (2010) 11:1203-10. doi: 10.1016/j.jpain.2010.02.006

128. Pleger B, Janssen F, Schwenkreis P, Volker B, Maier C, Tegenthoff M. Repetitive transcranial magnetic stimulation of the motor cortex attenuates pain perception in complex regional pain syndrome type I. Neurosci Lett. (2004) 356:87-90. doi: 10.1016/j.neulet.2003.11.037

129. Richlin DM, Carron H, Rowlingson JC, Sussman MD, Baugher WH, Goldner RD. Reflex sympathetic dystrophy: successful treatment by transcutaneous nerve stimulation. J Pediatrics. (1978) 93:84-6.

130. Robaina FJ, Rodriguez JL, de Vera JA, Martin MA. Transcutaneous electrical nerve stimulation and spinal cord stimulation for pain relief in reflex sympathetic dystrophy. Stereotact Funct Neurosurg. (1989) 52:5362. doi: $10.1159 / 000099486$

131. Schmid AC, Hummel FC, Birbaumer N. P19.13 pain reduction in a CRPS patient due to tDCS and sensorimotor training. A single case study. Clin Neurophysiol. (2011) 122:S144. doi: 10.1016/S1388-2457(11)60514-2

132. Stilz RJ, Carron H, Sanders DB. Reflex sympathetic dystrophy in a 6-yearold: successful treatment by transcutaneous nerve stimulation. Anesth Analg. (1977) 56:438-43. doi: 10.1213/00000539-197705000-00026

133. Wilder RT. Management of pediatric patients with complex regional pain syndrome. Clin J Pain. (2006) 22:4438. doi: 10.1097/01.ajp.0000194283.59132.fb

134. Passard A, Attal N, Benadhira R, Brasseur L, Saba G, Sichere P, et al. Effects of unilateral repetitive transcranial magnetic stimulation of the motor cortex on chronic widespread pain in fibromyalgia. Brain. (2007) 130:266170. doi: 10.1093/brain/awm189

135. Mhalla A, Baudic S, Ciampi de Andrade D, Gautron M, Perrot S, Teixeira MJ, et al. Long-term maintenance of the analgesic effects of transcranial magnetic stimulation in fibromyalgia. Pain. (2011) 152:147885. doi: 10.1016/j.pain.2011.01.034

136. Khedr E, Kotb H, Kamel N, Ahmed M, Sadek R, Rothwell J. Longlasting antalgic effects of daily sessions of repetitive transcranial magnetic stimulation in central and peripheral neuropathic pain. J Neurol Neurosurg Psychiatry. (2005) 76:833-8. doi: 10.1136/jnnp.2004.055806

137. Lefaucheur J-P, Drouot X, Menard-Lefaucheur I, Nguyen J. Neuropathic pain controlled for more than a year by monthly sessions of repetitie transcranial magnetic stimulation of the motor cortex. Neurophysiol Clin. (2004) 34:91-5. doi: 10.1016/j.neucli.2004.02.001

138. Lefaucheur $\mathrm{J}$. The use of repetitive transcranial magnetic stimulation (rTMS) in chronic neuropathic pain. Neurophysiol Clin. (2006) 36:11724. doi: 10.1016/j.neucli.2006.08.002

139. Kumru H, Albu S, Vidal J, Tormos JM. Effectiveness of repetitive trancranial or peripheral magnetic stimulation in neuropathic pain. Disabil Rehabil. (2017) 39:856-66. doi: 10.3109/09638288.2016.1170213

140. Gibson W, Wand BM, O'Connell NE. Transcutaneous electrical nerve stimulation (TENS) for neuropathic pain in adults. Cochrane Database Syst Rev. (2017) 9:CD011976. doi: 10.1002/14651858.CD01 1976.pub2

141. Ambriz-Tututi M, Alvarado-Reynoso B, Drucker-Colín R. Analgesic effect of repetitive transcranial magnetic stimulation (rTMS) in 
patients with chronic low back pain. Bioelectromagnetics.

(2016) 37:527-35. doi: 10.1002/bem.22001

142. Binny J, Wong NLJ, Garga S, Lin CWC, Maher CG, McLachlan AJ, et al. Transcutaneous electric nerve stimulation (TENS) for acute low back pain: systematic review. Scand J Pain. (2019) 19:225-33. doi: 10.1515/sjpain2018-0124

143. Galhardoni R, Correia GS, Araujo H, Yeng LT, Fernandes DT, Kaziyama $\mathrm{HH}$, et al. Repetitive transcranial magnetic stimulation in chronic pain: a review of the literature. Arch Phys Med Rehabil. (2015) 96:S156-72. doi: 10.1016/j.apmr.2014. 11.010

144. Hirayama A, Saitoh Y, Kishima H, Shimokawa T, Oshino S, Hirata M, et al. Reduction of intractable deafferentation pain by navigation-guided repetitive transcranial magnetic stimulation of the primary motor cortex. Pain. (2006) 122:22-7. doi: 10.1016/j.pain.2005.12.001

145. Töpper R, Foltys H, Meister IG, Sparing R, Boroojerdi B. Repetitive transcranial magnetic stimulation of the parietal cortex transiently ameliorates phantom limb pain-like syndrome. Clin Neurophysiol. (2003) 114:1521-30. doi: 10.1016/S1388-2457(03)00117-2

146. Baptista AF, Fernandes AMB, Sá KN, Okano AH, Brunoni AR, Lara-Solares A, et al. Latin American and Caribbean consensus on noninvasive central nervous system neuromodulation for chronic pain management (LAC2NIN-CP). Pain Rep. (2019) 4:e692. doi: 10.1097/PR9.0000000000000692
147. Cossins L, Okell RW, Cameron H, Simpson B, Poole HM, Goebel A. Treatment of complex regional pain syndrome in adults: a systematic review of randomized controlled trials published from june 2000 to february 2012 . Euro J Pain. (2013) 17:158-73. doi: 10.1002/j.1532-2149.2012.00217.x

Conflict of Interest: The authors declare that the research was conducted in the absence of any commercial or financial relationships that could be construed as a potential conflict of interest.

Publisher's Note: All claims expressed in this article are solely those of the authors and do not necessarily represent those of their affiliated organizations, or those of the publisher, the editors and the reviewers. Any product that may be evaluated in this article, or claim that may be made by its manufacturer, is not guaranteed or endorsed by the publisher.

Copyright (C) 2021 Zangrandi, Allen Demers and Schneider. This is an open-access article distributed under the terms of the Creative Commons Attribution License (CC BY). The use, distribution or reproduction in other forums is permitted, provided the original author(s) and the copyright owner(s) are credited and that the original publication in this journal is cited, in accordance with accepted academic practice. No use, distribution or reproduction is permitted which does not comply with these terms. 